\title{
再议中国的植被分类系统
}

\author{
宋永昌 阎恩荣* 宋坤
}

华东师范大学生态与环境科学学院, 上海 200241

摘 要 在《对中国植被分类系统的认知和建议》(简称《认知和建议》)的基础上, 参考近期国内外植被分类研究成果, 再 次讨论了中国植被分类系统和单位, 统一了各级单位划分依据, 增补了高、中、低各等级分类的具体建议, 并对《认知和建 议》一文中相关部分, 特别是植被型一级做了修订。将该修订方案与联合国教科文组织《世界植被分类与制图》、美国联邦 地理数据委员会《美国植被分类规范》，以及Braun-Blanquet的分类方案进行对比，以便于同行间相互了解和交流。

关键词 植被分类; 植被型; 群系; 群丛; 建议方案

引用格式: 宋永昌, 阎恩荣, 宋坤 (2017). 再议中国的植被分类系统. 植物生态学报, 41, 269-278. doi: 10.17521/cjpe.2016.0255

\section{An update of the vegetation classification in China}

\author{
SONG Yong-Chang, YAN En-Rong*, and SONG Kun \\ School of Ecological and Environmental Sciences, East China Normal University, Shanghai 200241, China
}

\begin{abstract}
The vegetation classification in China was updated by referring to recent advances for vegetation classification worldwide and on the basis of our former paper Recognition and Proposal on the Vegetation Classification System of China (hereafter, "Recognition and Proposal”). In this revision, the criteria for vegetation classification were discussed and unified, and a quantified standard for high, medium, and low level units in a new hierarchical classification scheme was supplemented. Compared with the old classification scheme in "Recognition and Proposal", the units at the level of vegetation type were substantially changed. Finally, in order to improve mutual communication among international peers, a comparison was carried out between the new revised scheme and each of International Classification and Mapping of Vegetation of UNESCO, The National Vegetation Classification Standard of United States, and The Braun-Blanquet Classification Scheme.
\end{abstract}

Key words vegetation classification; vegetation type; formation; association; suggested scheme

Citation: Song YC, Yan ER, Song K (2017). An update of the vegetation classification in China. Chinese Journal of Plant Ecology, 41, 269-278. doi: 10.17521/cjpe.2016.0255

编纂《中国植被志》是中国植物学界继编纂《中 国植物志》后的又一项巨大系统工程, 它是国家自 然资源本底的一项基础数据, 关系到国家的资源保 护和利用、生态环境优化和治理, 以及社会经济的 可持续发展。植被志编纂必然涉及植被分类系统和 单位, 正如编纂植物志首先必须确定植物分类系统 和单位。1980年出版的《中国植被》(中国植被编辑 委员会, 1980)一书所制定的植被分类原则和系统 (简称“80分类方案”)为中国植被志的编纂创造了有 利条件, 打下了良好的基础。30多年过去了, 历史证 明那时制定的中国植被分类原则是符合当时国际 植被分类发展趋势的, 但是关于分类单位设置和
划分的依据, 现在看来仍然存在一些问题。宋永 昌(2011)曾在《植物生态学报》上发表了《对中 国植被分类系统的认知和建议》 (以下简称《认知 与建议》), 在综合当时国际上植被分类和植被志 编辑动态的基础上, 对中国植被分类单位和系统 提出了调整的建议。2014年在中国科学院植物研 究所举办的 “ 《中国植被志》编研学术研讨会”上讨 论了中国植被分类系统。近期, 国际上, 特别是美国 在这方面的研究又有了一些发展(Faber-Langendoen et al., 2014), 国内也有讨论植被分类的文章发表(王 炜等, 2016), 促使我们对这一问题再行思考, 现拟 就中国植被分类系统和单位再谈一些看法, 不讳愚

收稿日期Received: 2016-08-02 接受日期Accepted: 2016-11-27

* 通信作者Author for correspondence (E-mail: eryan@des.ecnu.edu.cn) 
见，意在集思广益，并借此机会对2011年《认知与 建议》一文进行修正，就教于同行读者。

\section{1 对中国植被分类原则和系统的再认识}

“80分类方案”明确提出中国植被分类的原则 是: “植物群落学原则, 或植物群落学一生态学原则, 即主要以植物群落本身特征作为分类的依据, 但又 十分注意群落的生态关系, 力求利用所有能够利用 的全部特征……对不同等级的单位, 所采用的具 体指标不同，高级分类单位偏重于生态外貌，而中、 低级单位则着重种类组成和群落结构”。这一原则曾 经是Beard (1978)所期待的, 也是近年来美国一些 植被生态学家所采用的(Federal Geographic Data Committee, Vegetation Subcommittee, 2008; Jennings et al., 2009; Faber-Langendoen et al., 2012, 2014)。实 践证明, 对十分复杂的植被系统, 采用单一指标, 无论是生态外貌, 还是优势种, 或者是特征种进行 从高到低的全方位分类都是不现实的。无论从理论 上还是可操作性上看, 中国植被分类应该继续坚持 贯彻植物群落学—生态学原则。

受各种条件限制, “80分类方案”分类系统中的 单位设置和划分依据存在着一些值得商榷的问题, 主要有以下3点:

1) “80分类方案”的高等级单位共设“植被型 组”、“植被型”和“植被亚型” 3级，存在着一定的局 限性。首先, 当这个等级应用于大尺度地理区域时, 其分类单位显得过少, 无法归并具有相似特征的植 被型组, 也不便与国际上现有大多数植被分类系统 的高级单位衔接。此外, 该系统中的“植被型组”和 “植被型”两个等级重叠过多, 如草原、荒漠、冻原、 草甸、沼泽、水生植被等, 两个等级的不同只表现 在森林和灌从植被中。两种分类单位重叠将导致同 一等级的划分依据不能贯彻始终。例如针叶林、阔 叶林、灌丛和灌草丛、草原和稀树草原、荒漠、冻 原、高山稀疏植被、草甸、沼泽、水生植被这10个 植被型组, 它们的划分依据是不一致的, 同样该系 统也未能将植被型划分依据(建群种生活型相同或 相近, 同时对水热条件生态关系一致的植物群落联 合)完全贯彻于 29 个植被型的划分中。

2) “群系” (Formation)是“80分类方案”中的中级 单位，它的定义是: “凡建群种或共建种相同(在热 带或亚热带有时是标志种相同)的群落联合为群
系”，其中包含两个互相独立的指标——“优势种相 同”或“标志种相同”，容易导致一系列歧义，一旦当 研究者各取所需时, 将造成“群系”的不等价。此外, 如果把种的亲缘关系(物种相同)作为群落分类的首 要依据, 则有可能把优势种相同, 分布在不同植物 区系小区，生境条件区别很大的群丛划分为同一 “群系”; 相反，也会把优势种虽不完全相同，但分 布在同一植物区系小区，生境条件相似的群从划分 为不同“群系”。这样过分强调建群种亲缘关系的一 致性, 而弱化生态环境一致性的方法显然背离了 植被分类的基本原则。最后, Formation一词是 20 世纪50年代按苏卡切夫的定义 ${ }^{\circledR}$ 使用的，而国际间 自1872年Grisebach使用这个词以来, 绝大多数研究 者都把它用于较大的外貌分类单位, 即使在前苏联, 苏卡切夫对“Formation”的用法也未被普遍接受，而 在我国却得到了广泛使用, 这给我们与国际同行的 交流带来了极大的不便。

3)群丛是“80分类方案”植被分类的基本单位， 其定义为“凡是层片结构相同，各层片的优势种或 共优种(南方某些类型中则为标志种)相同的植物群 落联合”。显然这个定义中也含有两个互相独立的划 分标准, 一是按各层优势种或共优种相同划分群丛, 一是按标志种划分群丛, 前者划分出的“群丛”是早 期瑞典学派的基群丛(Sociation), 后者划分出的“群 从”接近于法瑞学派的群从, 因此, 不等值的情况将 在同一系统内发生。

\section{2 再谈中国植被分类系统的调整}

针对上述问题，笔者建议对中国植被分类系统 单位做如下调整(简称“建议方案”)(表1)。

\section{1 关于高级单位的调整}

“建议方案”中的高级单位, 在“80分类方案” 中的“植被型组”、“植被型”和“植被亚型”基础上 增加“植被纲”和“植被亚纲”, 并对各级划分标准做 统一调整。

植被纲: 是按一级生长型(乔木、灌木、草本) 以及对极端生境(极端干旱、极端寒冷、极端多水) 适应而形成的外貌类型，共分6个植被纲(附录I), 其 中森林、灌从和草本植被, 是以适应近中生条件的 生长型所形成生态外貌划分的, 荒漠、冻原和湿地

(1) “主要层具有相同优势种的群丛, 连合成一个群系” (转引自: Aleksandrova, 1985)。 
表1 “建议方案”与“80分类方案”的比较

Table 1 Comparison between "recommend scheme" and "80 classification scheme" for the vegetation classification in China

\begin{tabular}{ll}
\hline 80 分类方案 80 Classification scheme & 建议方案 Recommend scheme \\
\hline 高级单位(生态外貌) High level (Eco-physiognomic) & \\
& 植被纲 Class of vegetation types \\
& 植被亚纲 Subclass of vegetation types \\
植被型组 Group of vegetation types & 植被型组 Group of vegetation types \\
植被型 Vegetation type & 植被型 Vegetation type \\
植被亚型 Vegetation subtype & 植被亚型 Vegetation subtype \\
中级单位(区系特征, 着重优势种组成) Midle level (Floristc, emphasizing dominant species) & \\
群系组 Formation group & 集群 Collective group \\
群系 Formation & 优势度型 Dominant type \\
亚群系 Subformation & 优势度亚型 Dominant subtype \\
低级单位(区系特征, 着重标志种组) Low level (Floristic, emphasizing symbol species) & \\
群丛 Association & \\
\hline & 群丛 Association \\
\hline
\end{tabular}

类型中虽不只一种生长型，但它们在适应极端生境 中形成具有共同特征的生态外貌, 因此植被纲的划 分标准基本是一致的。植被亚纲是按二级生长型(针 叶、阔叶、竹叶等), 以及与区域气候有联系的生态 特征划分的, 共调整为 14 个(附录I)。这样, 在中国植 被分类系统中增加了植被纲和亚纲后就可与联合国 教科文组织制定的《世界植被分类与制图》(United Nations Educational, Scientific and Cultural Organization, 1973), 以及美国联邦地理数据委员会制定的

《美国植被分类规范》(Federal Geographic Data Committee, Vegetation Subcommittee, 2008)中高级 单位群系纲(Formation class)、群系亚纲(Formation subclass) 衔接一致了。这里没有采用群系纲 (Formation class)一词, 是因为“群系”在中国习惯用 语中有非常不同的含义, 为免误解, 采用了植被纲 和植被亚纲的名称。

植被型组: 是根据优势层优势种的三级生长型 (常绿、落叶、硬叶等叶的生活期或物候性状), 以及 特殊生境(海岸、淡水、咸水、高山等)划分的生态 外貌类型。如森林中的落叶针叶林、常绿针叶林、 针阔叶混交林、落叶阔叶林、常绿落叶阔叶混交林、 常绿苔蘚林、常绿硬叶林、常绿阔叶林、热带雨林、 热带季雨林、海岸林、竹林, 再如灌从中的常绿针 叶灌从、常绿革叶灌从、落叶阔叶灌从、常绿榈叶 灌从、肉刺灌从、竹灌从，草本植被中的温带草原、 稀树草原、高山草原、草甸、疏灌草坡, 极端干旱 植被中的温带荒漠、高山荒漠, 极端寒冷植被中的 高山冻原、高山垫状植被、高山流石堆植被, 极端
多水植被中的沼泽、淡水水生植被、咸水水生植被, 共31个植被型组(附录I)。这一级相当于“80分类方 案”中的“植被型”。

植被型：依然是高等级的核心单位，其定义调 整为: “与一定的生态气候带或亚带相联系的, 或与 特殊的生境类型相关联的, 分布在一定植物区系分 布区的, 具有相似外貌和优势生长型的生态外貌类 型”。强调它们属于水平带或山地垂直带上的气候顶 极(climatic climax); 或独特地形、土壤的地文顶极 (physiographic climax); 或受强度干扰的偏途顶极 (disclimax)或歧顶极(plaigioclimax)。如: 落叶阔叶林 中的典型落叶阔叶林(温带湿润区域的地带型植被), 山地落叶阔叶林(温带、亚热带山地垂直带上分布的 杨柳科与桦木科小叶种占优势的植被); 河岸滩地 落叶阔叶林 (与地下水相联系特殊生境中的地文顶 极); 次生落叶阔叶林(亚热带地区人为干扰下的歧 顶极)。再如常绿阔叶灌从中的南方丘陵山地常绿阔 叶灌从(亚热带地区歧顶极), 滨海岛礁常绿榈叶灌 丛(地文顶极)等, 这一等级与“80分类方案”中的“植 被亚型”相当, 也相当于英美学者及西欧学者根据 外貌确定的 “群系(Formation) ${ }^{\circledR}$ ”。与此处植被型 (Vegetation type)相比, 除未强调大范围分布外, 含 义基本相同。

需要指出的是, 这里共划分出 72 个植被型(附 录I), 与 《认知与建议》一文中的植被型划分有较大 不同, 主要是关于草甸和草原分类, 在《认知与建

(1) 定义是: “大范围(全球)分布的、具有相似外貌和优势生长型的、并与 主要地貌和土壤条件相联系的、出现在大气候条件下的植物群落。” 
议》一文中将禾草生态习性(丛生、根茎), 以及草群 种类(禾草、杂类草)作为分类的首要依据, 降低了生 态外貌和地理分布的原则, 因而将这两类植被划分 出 29 个植被型, 现在则减少为 11 个, 结果使得这里 的“植被型”与 “80分类方案” 中的“植被亚型”数量 (61)相近。

植被亚型: 是植被型下的一个辅助级, 它是与 一定地理区域和植物区系地区有联系的, 以一组与 区域气候和环境条件相关的优势生长型和标志种为 特征的外貌类型。例如典型常绿榈叶林植被型下再 按不同区域, 以及所联系的区系成分和气候特征划 分为东部典型常绿阔叶林亚型、西部典型常绿阔叶 林亚型, 以及台湾山地典型常绿阔叶林亚型; 又如 亚高山革叶灌从下划分的青藏高原亚高山革叶灌从 亚型、川滇亚高山革叶灌从亚型, 以及台湾亚高山 革叶灌丛亚型; 再如灌木荒漠下划分为阔叶灌木荒 漠亚型、肉质叶灌木荒漠亚型、退化叶灌木荒漠亚 型。在植被亚型命名中虽然出现了地理区域名称, 但主要依据还是区系成分。

将《中国植被》(1980)分类系统中的“植被型” 提升为“植被型组”, 将“植被亚型”提升为“植被型”, 这样可使“植被型组”包括分布在不同区域, 具有不 同区系背景, 以及水平带和垂直带上分布的生态外 貌相同的类型; 而“植被型”必定和一定的气候带或 亚带, 或独特的地貌类型、环境条件相联系, 具有一 定区系背景的类型。“植被型”是高级单位的核心, 是开放的, 可因研究的深入和需要而增减。

\section{2 关于中级单位的调整}

“建议方案” 中设置 3 个中级单位：集群 (Collective group)、优势度型(Dominant type)和优势 度亚型(Dominant subtype)。

优势度型：是中级单位的核心，它的定义是： “优势层片的优势种相同, 或生态习性一致, 并具有 相同标志种的群丛的联合”。这一级相当于 “80分类 方案”的“群系” (Formation), 不同之处是：这里明 确指出这一级分类依据不限于优势层片的优势种 相同, 也包括优势种生态习性的一致, 但同时都必 须具有相同标志种的群丛的联合。此外, 为方便国 际间交流，建议放弃 “Formation”一词，采用 Whittaker (1978)的“优势度型” (Dominant type), 如 果考虑与国际上主要分类系统衔接, 也可使用 “Alliance” (群团)。
优势度亚型: 是优势度型下的一个辅助单位, 它可以根据优势种组成, 或生态习性差异, 以及分 布地区的不同而划分。

集群：是优势度型的上级单位，它是“优势层 片中优势种的生活型一致、生态习性相似，并具有 相应标志种的优势度型的联合, 一般具有一定的分 布区，或占有特殊的生境”。这个等级相当于“80分 类方案”的“群系组”，它们的不同之处是 “集群”不 再强调优势种的亲缘关系, 而更重视优势种生态习 性的近似、一定的分布区域, 和具有相同的标志种。 这样也就解决了“80分类方案”中将建群种亲缘关系 的一致性原则超越生态环境一致性原则的不足。 例如在新方案中, 不再将以青冈(Cyclobalanopsis glauca)占优势的分布在大陆东部的青冈优势度型 和以滇青冈(Cyclobalanopsis glaucoides)占优势的分 布在大陆西部的滇青冈优势度型，以及以台湾青冈 (Cyclobalanopsis morii)占优势的分布在台湾的台湾 青冈优势度型归为一个青冈林 “群系组” (Cyclobalanopsis Formation)。它们分别属于东部青 冈-柯-栲集群(Eastern Cyclobalanopsis-LithocarpusCastanopsis Collective group), 西部青冈-栲集群 (Western Cyclobalanopsis-Castanopsis Collective group) 和台湾山地青冈集群 (Taiwan montane Cyclobalanopsis-Castanopsis-Lithocarpus Collective group), 它们的标志种分别是: 青冈、滇青冈 和台 湾青冈(宋永昌等, 2013)。这样的等级在某种程度上 接近于法瑞学派的“群落目” (Order), 同样原因, 此 处采用Whittaker (1978)建议的“集群” (Collective group)。

\section{3 关于低级单位的调整}

群从是植被分类的基本单位, 为避免南方和北 方“群从”的不等质，建议将其定义修订为：群丛是 “层片结构相同, 优势层片优势种相同, 种类组成基 本一致, 并具有相同标志种组的群落联合” (宋永 昌, 2004, 2011)。这里不再强调“各层片的优势种相 同”, 而只要求优势层片优势种相同, 种类组成基本 一致, 并规定群丛必须具有一致的“标志种”。这里 的“标志种” (indicative species或symbolic species), 意指任何植物分类单位或分类群, 其存在度或多度 足以将某一植被类型与另一植被类型相区别, 它的 含义较广, 相当于鉴别种(diagnostic species), 由于 强调标志种的一致, 可使划分出来的每一群从必然 
具有相同的生态特征、生境条件和动态特点。用这 一定义划分出来的“群从” 是可以和法瑞学派的“群 从” (是一个植物区系成分上一致的植物群落, 它与 外界因子或多或少处于平衡之中, 并通过为该群从 所特有的特征种的存在, 显示出生态上的独立性 (Braun-Blanquet et al., 1932))对比的。这样划分出来 的“群丛”较之单纯以各层优势种一致所划分出来的 “群从”要大些。

考虑到以往文献中的许多“群丛”都是按各层优 势相同确定的, 建议保留它作为“群从”的下级单位, 称基群丛(Sociation)。此外, 按法瑞学派观点, “群 丛”下的次级分类单位: 依局部土壤或微气候划分 的是亚群丛(Subassociation); 依地理或气候差异划 分的是变型 (variant), 或称地理群宗 (geographic race); 依不同演替状况划分则是相(phase)。这些次 级分类单位可根据研究需要而定。

修订后的中国植被分类系统1级到4级见附录 I。 这个分类系统仅涉及自然植被和半自然植被, 至于 栽培植被的分类, 原则上与自然植被相同, 但是栽 培植被的存在与发展深受社会发展和经济技术水平 的影响, 在栽培植被分类时, 必须考虑到栽培植被 的这种特殊性。

\section{3 与国际上几种植被分类系统的比较}

“建议方案”与国际上其他几种主要分类系统 的比较见表2。

3.1 “建议方案” 和 “联合国教科文组织方案” (UNESCO, 1973)的比较

“联合国教科文组织方案” 最初是由Ellenberg和 Mueller-Dombois在1967年拟定(《Tetative Physiognomic-ecological Classification of the Main Plant Formations of the Earth》), 后经讨论修改, 于1973 年正式以《International Classification and Mapping of Vegetation》(UNESCO, 1973)发布。整个方案除草本 植被分类有较大改动外，其他类型与1967年相同。 该方案属于生态外貌分类, 设置的等级单位依次 是: 群系纲—群系亚纲—群系组一群系一亚群系。 其中群系纲分为: 密林 (Closed forest)、疏林 (Woodlands)、灌丛 (Scrub)、矮灌丛与相关群落 (Dwarf-scrub and related communities), 以及草本植 被(Herbaceous vegetation)。“密林”、“疏林”、“灌丛”、 “矮灌从”下的亚纲是按常绿或落叶划分的, 草本植
被下的亚纲是按禾草高度、杂类草, 以及浸水程度 划分的; “群系组”多是与大气候相联系的生态外貌 类型, 例如热带适雨林、热带亚热带常绿季节林、 亚热带适雨林等; “群系”则是与一定地形部位、特殊 生境条件相关的外貌类型，如热带适雨林下分为: 热带低地适雨林、热带低山适雨林、热带山地适雨 林、热带亚高山适雨林、热带泛滥低地适雨林等。 从比较中可见“建议方案” 和“联合国教科文组织方 案” 中的高级单位设置是相对应的, 划分的依据 也是近似的, 前者的核心单位是 “植被型”, 后者 的核心单位是“群系”, 它们都是气候顶极, 或地形 顶极。在森林和灌从的亚纲划分中, “联合国教科文 组织方案” 采取的是先常绿、落叶, 而后是针叶、阔 叶, “建议方案”则相反, 是先针叶、阔叶, 而后是常 绿、落叶等。前者的优点是便于遥感分类和植被制 图, 而后者更着重于植被演化, 以及传统使用习惯 和方便于林业、草业实际应用。

\section{2 “建议方案”和“Braun-Blanquet方案”比较}

“Braun-Blanquet方案”是应用最广泛、最标准化 的植被分类方案, 基本单位是“群从”, 它是通过一 组样地记录归并得出的, 其上级单位依次再聚合为 “群团” (Alliance)、“群落目” (Order)和群落纲(Class), 分类的指标均以特征种为依据。“Braun-Blanquet方 案”对低中级单位的分类最为有效, 其“群丛”被公 认为正规的基本分类单位。“建议方案”的中低级单 位划分的依据, 因受目前研究资料所限, 没有采用 严格意义上的特征种, 而是利用标志种, 同时强调 种类组成的相似性, 在一定程度上也是可以兼容的。

“Braun-Blanquet方案” 中高级单位的划分, 由 于研究范围扩大, 特征种意义降低, 随着世界各 地植被研究的开展, 群落纲数目不断增加, 为了 比较归纳, 在群落纲以上有必要建立更高级的单 位。近年来采用的一种做法是: 在群落纲名称之 上再按生态外貌归并为群系(Formation), 如水生 植物群系、中欧干草地群系、高山草地群系、矮 灌木群系、灌木群系、森林群系(Wilmanns, 1998)。 这样, 该方案的高级单位也就和采用生态外貌的 高级分类相衔接。

\section{3 “建议方案”与《美国植被分类规范》的比较}

美国联邦地理数据委员会(The United States Federal Geographic Data Committee)下属的植被分会, 于1997年发布《Vegetation Classification Standard》, 
表2 “建议方案”与几种植被分类系统的比较

Table 2 Comparisons between "recommend scheme" and the schemes proposed by the UNESCO (1973), Federal Geographic Data Committee (FGDC, 2008), and Braun-Blanquet et al. (1932)

\begin{tabular}{llll}
\hline 建议方案 (Song, 2011) & UNESCO (1973) & Federal Geographic Data Committee (FGDC, 2008) & Braun-Blanquet et al. (1932) \\
\hline 植被纲 Vegetation class & 群系纲 Formation class & 群系纲 Formation class & \\
植被亚纲 Vegetation subclass & 群系亚纲 Formation subclass & 群系亚纲 Formation subclass & \\
植被型组 Vegetation type group & 群系组 Formation group & & 群落纲 Class \\
植被型 Vegetation type & 群系 Formation & 群系 Formation & 群落目 Order \\
植被亚型 Vegetation subtype & 亚群系 Subformation & 门类 Division & \\
集群 Collective group & & 大组 Macro-group & 群团 Alliance \\
& & 组 Group & 群从 Association \\
优势度型 Dominant type & & 群团 Alliance & 群丛 Association \\
群从 Association & &
\end{tabular}

2006年发布第2版，2012年由Faber-Langendoen等人 集成《Classification and description of world formation types》 (Faber-Langendoen et al., 2012)。《美国植 被分类规范》采用的高级单位的分类依据是植被的 结构外貌，中级单位分类的依据是群落的外貌和种 类组成, 低级单位分类的依据是种类组成, 尤其是 标志种(鉴别种)。这个方案与“建议方案”基本一致, 各级单位的设置大致相同, 只是在某些类型以及亚 类的处理上有差别。如《美国植被分类规范》的群 系纲分为: 森林和疏林(Forest \& Woodland)、灌丛和 草地(Shrubland \& Grassland)、半荒漠(Semi-desert vegetation)、极地和高山植被(Polar \& High montane vegetation)、水生植被(Aquatic vegetation), 以及非维 管和稀疏维管植被(Nonvascular \& Sparse vascular vegetation)。其次, 群系亚纲的划分原则与“联合国 教科文组织方案”相同。

中级单位设置 3 级: 门类 (Division)、大组 (Macro-group)、组(Group)。划分标准重视优势生长 型、鉴别种(包括种和属任何分类单位), 以及地理分 布范围。它们与“建议方案”中“集群”定义相近，但 集群没有限定地理范围, 它可能包含组(Group)和大 组(Macro-group), 今后随着研究范围扩大, 也可能 需要在集群上增加一个等级——“集群组”, 以概括 分布在不同地域内的相近集群。

《美国植被分类规范》采用的低级单位是“群 从一 (Association)和“群团” (Alliance), 划分原则与 “建议方案”类似，两者是可以衔接的。

\section{4 结语}

当今世界已进入全球化时代, 各国之间各个
领域的联系日益加强，植被科学研究也不例外， 尤其是植被分类需要进行全球统合，中国植被是 全球植被的重要组成部分，应在建立全球植被分 类系统中发挥作用。《中国植被志》的出版不仅是 中国植被学界的一件大事, 也将在国际植被学界 产生重大影响, 它所采用的植被分类既要符合中 国植被特点, 又要适应国际植被分类的发展趋 势, 便于和国际上主要分类方案沟通衔接。这就 需要加强沟通，形成更多的共同语言，在名词概 念统一的基础上, 内涵实质逐步统一, 从而建立 起统一的全球植被分类系统。

组成植被的群落是自然界中极其复杂的现象, 它不仅具有生物属性，也具有地理属性，而且还有 社会属性。对如此复杂的系统进行分类，困难可想 而知。尽管植被科学已有 200 多年历史，但直到现 在并没有一个能为植被学家共同接受的统一的分 类原则和分类系统，而分类又是任何科学研究的 基础, 也是该门学科研究成果和水平的集中体现。

《中国植被志》采用的分类系统原则上应能反映 当代植被科学研究水平，适应植被分类发展趋 势, 并具有较大的包容性和扩展潜力。对于其中 的核心单位，如高级单位“植被型” (相当于国际 上的Formation)、中级单位“优势度型” (以往称“群 系”，相当于国际上的Alliance), 以及基本单位“群 从” 需要有统一的分类标准和原则, 以保证其科学 性和稳定性。

《中国植被志》是国家自然资源本底的基础数 据, 它的编纂应遵循科学性原则, 只要具有严格的 科学性，就能适应现在和将来的应用，因为应用的 范围是在不断扩展的，不能把植被志编成为适应某 
一行业需要的使用手册, 它们的任务是有区别的。

此外, 在《中国植被志》编纂过程中除了要涉 及植被分类系统单位外, 群落命名也是不能回避的 问题。我国的群落命名, 特别是中低级单位命名方 法不一, 缺少一致的标准, 值此《中国植被志》编纂 之际, 建立统一的命名法规显得尤为必要, 希望主 编单位广泛征求意见, 组织讨论, 集思广益, 尽快 制定出统一的命名法规。

基金项目 国家自然科学基金(31270475和31500355)。

\section{参考文献}

Beard JS (1985). The physiognomic approach. In: Whittaker RH ed. Translated by Zhou JL. Classification of Plant Communities. Science Press, Beijing. 13, 20-46. (in Chinese) [周纪伦译 (1985). 植物群落分类. 科学出版社, 北京. 13, 20-46.]

Braun-Blanquet J (1932). Translated by Braun-Blanquet J, Fuller GD, Conrad HS. Plant Sociology - The Study of Plant Communities. McGrawhill, New York. 439. (in English)

Faber-Langendoen D, Keeler-Wolf T, Meidinger D, Josse C, Weakley A, Tart D, Navarro G, Hoagland B, Ponomarenko S, Saucier JP, Fults G, Helmer E (2012). Classification and description of world formation types. Part I (Introduction) and Part II (Description of formation types). Hierarchy Revisions Working Group, Federal Geographic Data Committee, FGDC Secretariat, U.S. Geological Survey. Reston, VA, and NatureServe, Arlington, VA.

Faber-Langendoen D, Keeler-Wolf T, Meidinger D, Tart D, Hoagland B, Josse C, Navarro G, Ponomarenko S, Saucier JP, Weakley A, Comer P (2014). EcoVeg: A new approach to vegetation description and classification. Ecological Monographs, 84, 533-561.

Federal Geographic Data Committee, Vegetation Subcommittee (FGDC-VS) (2008). The National Vegetation Classification Standard. Version 2. FGDC-STD-005-2008 (Version 2). 126.

Jennings MD, Faber-Langendoen D, Louckes OL, Peet RK, Roberts D (2009). Standards for associations and alliances of the U.S. National Vegetation Classification. Ecological Monographs, 79, 173-199.

Song YC (2004). Tentative classification scheme of evergreen broad-leaved forests of China. Acta Phytoeclogica Sinica, 28, 435-448. (in Chinese with English abstract) [宋永昌 (2004). 中国常绿阔叶林分类试行方案. 植物生态学 报, 28, 435-448.]

Song YC (2011). Recognition and proposal on the vegetation classification system of China. Chinese Journal of Plant Ecology, 35, 882-892. (in Chinese with English abstract) [宋永昌 (2011). 对中国植被分类系统的认知 和建议. 植物生态学报, 35, 882-892.]

Song YC, Wang XH, Yan ER (2013). Evergreen Broad-leaved Forest of China-Classification, Ecology, Conservation. Science Press, Beijing. 801, 558. (in Chinese) [宋永昌, 王希华, 阎恩荣 (2013). 中国常绿阔叶林一一分类, 生态, 保育. 科学出版社, 北京. 801, 558.]

The Editorial Committee of Vegetation of China (1980). Vegetation of China. Science Press, Beijing. 1375. (in Chinese) [中国植被编辑委员会 (1980). 中国植被. 科学出版社, 北京. 1375.]

United Nations Educational, Scientific and Cultural Organization (UNESCO) (1973). International Classification and Mapping of Vegetation. Series 6. Ecology and Conservation. United Nations, Paris, France.

Wang W, Pei H, Wang XT (2016). A logistic analysis on vegetation classification system based on dominant species with an illustrational scheme. Biodiversity Science, 24, 136-147. (in Chinese with English abstract) [王炜, 裴浩, 王金锤厅 (2016). 优势种植被分类系统的逻辑分析与示 例方案化. 生物多样性, 24, 136-147.]

Whittaker RH (1985). Dominance-types. In: Whittaker RH ed. Translated by Zhou JL. Classification of Plant Communities. Science Press, Beijing. 47-59. (in Chinese) [周纪伦 译 (1985). 植物群落分类. 科学出版社, 北京. 47-59.]

Wilmanns O (1998). Ökologische Pflanzensoziologie 6th edn. Quelle \& Meyer Verlag, Wiesbaden. 405. (in German)

责任编委: 郭 柯 责任编辑: 谢 巍

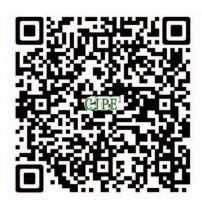

植物生态学报官网

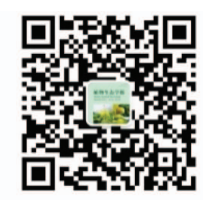

微信订阅号

期刊及学科

相关信息发布

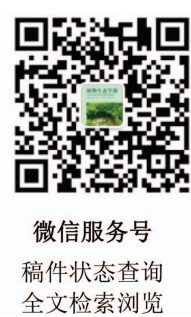

全文检索汶览 
附录I 中国植被分类的高级单位

Appendix I High level units (1-4) of the vegetation classification in China

\begin{tabular}{|c|c|c|c|}
\hline 1级 Class 1 & 2级 Class 2 & 3级 Class 3 & 4级 Class 4 \\
\hline $\begin{array}{l}\text { 植被纲 } \\
\text { Class of vegetation } \\
\text { types }\end{array}$ & $\begin{array}{l}\text { 植被亚纲 } \\
\text { Subblass of } \\
\text { vegetation types }\end{array}$ & $\begin{array}{l}\text { 植被型组 } \\
\text { Group of vegetation types }\end{array}$ & $\begin{array}{l}\text { 植被型 } \\
\text { Vegetation type }\end{array}$ \\
\hline \multirow[t]{11}{*}{$\begin{array}{l}\text { 二、森林 } \\
\text { Forest }\end{array}$} & $\begin{array}{l}\text { I. 针叶林 } \\
\text { Needle-leaved } \\
\text { forest }\end{array}$ & $\begin{array}{l}\text { 1. 落叶针叶林 } \\
\text { Deciduous needle-leaved } \\
\text { forest }\end{array}$ & $\begin{array}{l}\text { 1)典型寒温性落叶针叶林(地带性, 气候顶极) } \\
\text { Typical cold-temperate deciduous needle-leaved forest (Zonality, climatic climax) } \\
\text { 2)山地寒温性落叶针叶林(亚高山垂直带) } \\
\text { Montane cold-temperate deciduous needle-leaved forest (Subalpine vertical zone) } \\
\text { 3)暖性落叶针叶林(子遗群落) } \\
\text { Warm deciduous needle-leaved forest (Relict community) }\end{array}$ \\
\hline & & $\begin{array}{l}\text { 2. 常绿针叶林 } \\
\text { Evergreen needle-leaved } \\
\text { forest }\end{array}$ & $\begin{array}{l}\text { 4)典型寒温性常绿针叶林(地带性, 气候顶极) } \\
\text { Typical cold-temperate evergreen needle-leaved forest (Zonality, climatic climax) } \\
\text { 5)山地寒温性常绿针叶林(亚高山垂直带) } \\
\text { Montane cold-temperate evergreen needle-leaved forest (Subalpine vertical zone) } \\
\text { 6)温性常绿针叶林(地带性, 偏途顶极) } \\
\text { Temperate evergreen needle-leaved forest (Zonality, disclimax) } \\
\text { 7)暖性常绿针叶林(地带性, 偏途顶极) } \\
\text { Warm evergreen needle-leaved forest (Zonality, disclimax) } \\
\text { 8)热性常绿针叶林(地带性, 偏途顶极) } \\
\text { Torrid evergreen needle-leaved forest (Zonality, disclimax) }\end{array}$ \\
\hline & $\begin{array}{l}\text { II. 针阔叶混交林 } \\
\text { Mixed } \\
\text { needle-broad } \\
\text { leaved forest }\end{array}$ & $\begin{array}{l}\text { 3. 针阔叶混交林 } \\
\text { Mixed needle-broad } \\
\text { leaved forest }\end{array}$ & $\begin{array}{l}\text { 9)典型凉温性针阔叶混交林(地带性, 气候顶极) } \\
\text { Typical cool-temperate mixed needle-broad leaved forest (Zonality, climatic climax) } \\
\text { 10)山地针阔叶混交林(山地垂直带) } \\
\text { Montane mixed needle-broad leaved forest (Montane vertical zone) } \\
\text { 11)次生针阔叶混交林(地带性, 偏途顶极) } \\
\text { Secondary mixed needle-broad leaved forest (Zonality, disclimax) }\end{array}$ \\
\hline & $\begin{array}{l}\text { III. 阔叶林 } \\
\text { Broad-leaved } \\
\text { forest }\end{array}$ & $\begin{array}{l}\text { 4. 落叶阔叶林 } \\
\text { Deciduous broad-leaved } \\
\text { forest }\end{array}$ & $\begin{array}{l}\text { 12)典型落叶阔叶林 (地带性, 气候顶极) } \\
\text { Typical deciduous broad-leaved forest (Zonality, climatic climax) } \\
\text { 13)山地落叶阔叶林(山地垂直带) } \\
\text { Montane deciduous broad-leaved forest (Montane vertical zone) } \\
\text { 14)河岸落叶阔叶林 (地文顶极) } \\
\text { Riverside deciduous broad-leaved forest (Physiographic climax) } \\
\text { 15)次生落叶阔叶林 (地带性, 歧顶极) } \\
\text { Secondary deciduous broad-leaved forest (Zonality plaigioclimax) }\end{array}$ \\
\hline & & $\begin{array}{l}\text { 5. 常绿落叶阔叶混交林 } \\
\text { Mixed evergreen } \\
\text { deciduous broad-leaved } \\
\text { forest }\end{array}$ & $\begin{array}{l}\text { 16)典型常绿落叶阔叶混交林(地带性, 气候顶极) } \\
\text { Typical mixed evergeen deciduous broad-leaved forest (Zonality, climatic climax) } \\
\text { 17)山地常绿落叶阔叶混交林(山地垂直带) } \\
\text { Montane mixed evergreen deciduous broad-leaved forest (Montane vertical zone) } \\
\text { 18)石灰岩常绿落叶阔叶混交林(地文顶极) } \\
\text { Limestone mixed evergreen deciduous broad-leaved forest (Physiographic climax) } \\
\text { 19)河谷常绿落叶阔叶混交林(地文顶极) } \\
\text { Ravine mixed evergreen deciduous broad-leaved forest (Physiographic climax) }\end{array}$ \\
\hline & & $\begin{array}{l}\text { 6. 常绿苔蘚林 } \\
\text { Evergreen mossy forest }\end{array}$ & $\begin{array}{l}\text { 20)山地常绿苔蘚林(山地垂直带) } \\
\text { Montane dwarf evergreen mossy forest (Montane vertical zone) }\end{array}$ \\
\hline & & $\begin{array}{l}\text { 7. 常绿硬叶林 } \\
\text { Evergreen sclerophyllous } \\
\text { forest }\end{array}$ & $\begin{array}{l}\text { 21)山地常绿硬叶林(山地垂直带) } \\
\text { Montane evergreen sclerophyllous forest (Montane vertical zone) } \\
\text { 22)干热河谷常绿硬叶林(地文顶极) } \\
\text { Xerothermic valley Evergreen sclerophyllous forest (Physiographic climax) }\end{array}$ \\
\hline & & $\begin{array}{l}\text { 8. 常绿阔叶林 } \\
\text { Evergreen broad-leaved } \\
\text { forest }\end{array}$ & $\begin{array}{l}\text { 23)典型常绿阔叶林(地带性, 气候顶极) } \\
\text { Typical evergreen broad-leaved forest (Zonality, climatic climax) } \\
\text { 24)季节常绿阔叶林(地带性, 气候顶极) } \\
\text { Seasonal evergreen broad-leaved forest (Zonality, climatic climax) } \\
\text { 25)适雨常绿阔叶林(亚热带雨林)(地带性, 气候顶极) } \\
\text { Ombrophilous evergreen broad-leaved forest (Zonality, climatic climax) }\end{array}$ \\
\hline & & $\begin{array}{l}\text { 9. 热带雨林 } \\
\text { Tropical rain-forest }\end{array}$ & $\begin{array}{l}\text { 26)热带雨林(地带性, 气候顶极) } \\
\text { Tropical rain forest (Zonality, climatic climax) } \\
\text { 27)季节热带雨林(地带性, 气候顶极) } \\
\text { Tropical seasonal rain forest (Zonality, climatic climax) }\end{array}$ \\
\hline & & $\begin{array}{l}\text { 10. 热带季雨林 } \\
\text { Tropical monsoon forest }\end{array}$ & $\begin{array}{l}\text { 28)落叶季风雨林(地带性, 气候顶极) } \\
\text { Tropical deciduous monsoon forest (Zonality, climatic climax) } \\
\text { 29)半落叶季风雨林(地带性, 气候顶极) } \\
\text { Semi-deciduous monsoon forest (Zonality, climatic climax) }\end{array}$ \\
\hline & & $\begin{array}{l}\text { 11. 热带海岸林 } \\
\text { Tropical coastal forest }\end{array}$ & $\begin{array}{l}\text { 30)红树林(地文顶极) } \\
\text { Mangrove (Physiographic climax) }\end{array}$ \\
\hline
\end{tabular}


附录I (续) Appendix I (continued)

\begin{tabular}{|c|c|c|c|}
\hline 1级 Class 1 & 2级 Class 2 & 3级 Class 3 & 4级 Class 4 \\
\hline 植被纲 & 植被亚纲 & 植被型组 & 植被型 \\
\hline $\begin{array}{l}\text { Class of vegetation } \\
\text { types }\end{array}$ & $\begin{array}{l}\text { Subclass of } \\
\text { vegetation types }\end{array}$ & Group of vegetation types & Vegetation type \\
\hline \multirow{9}{*}{$\begin{array}{l}\text { 二、灌丛 } \\
\text { Shrubland }\end{array}$} & & & $\begin{array}{l}\text { 31)珊瑚礁海岸林(地文顶极) } \\
\text { Coral reef coastal forest (Physiographic climax) }\end{array}$ \\
\hline & $\begin{array}{l}\text { IV. 竹林 } \\
\text { Bamboo forest }\end{array}$ & $\begin{array}{l}\text { 12. 竹林 } \\
\text { Bamboo forest }\end{array}$ & $\begin{array}{l}\text { 32)暖性竹林(地带性, 偏途顶极) } \\
\text { Warm bamboo forest (Zonality, disclimax) } \\
\text { 33)热性竹林(地带性, 偏途顶极) } \\
\text { Torrid bamboo forest (Zonality, disclimax) }\end{array}$ \\
\hline & $\begin{array}{l}\text { V. 针叶灌从 } \\
\text { Needle-leaved } \\
\text { shruland }\end{array}$ & $\begin{array}{l}\text { 13. 常绿针叶灌丛 } \\
\text { Evergreen needle-leaved } \\
\text { shrubland }\end{array}$ & $\begin{array}{l}\text { 34)亚高山常绿针叶灌丛(亚高山垂直带) } \\
\text { Subalpine evergreen needle-leaved shrubland (Subalpine vertical zone) }\end{array}$ \\
\hline & $\begin{array}{l}\text { VI. 阔叶灌从 } \\
\text { Broad-leaved } \\
\text { shrubland }\end{array}$ & $\begin{array}{l}\text { 14. 常绿革叶灌从 } \\
\text { Evergreen sclerophyllous } \\
\text { shrubland }\end{array}$ & $\begin{array}{l}\text { 35)亚高山常绿革叶灌丛(亚高山垂直带) } \\
\text { Subalpine evergreen sclerophyllous shrubland (Subalpine vertical zone) }\end{array}$ \\
\hline & & $\begin{array}{l}\text { 15. 落叶阔叶灌从 } \\
\text { Deciduous broad-leaved }\end{array}$ & $\begin{array}{l}\text { 36)亚高山落叶阔叶灌丛(亚高山垂直带) } \\
\text { Subalpine deciduous broad-leaved shrubland (Subalpine vertical zone) }\end{array}$ \\
\hline & & shrubland & $\begin{array}{l}\text { 37)温性落叶阔叶灌丛(地带性，歧顶极) } \\
\text { Temperate deciduous broad-leaved shrubland (Zonality, plaigiographic climax) } \\
\text { 38)暖性落叶阔叶灌 丛(地带性, 歧顶极) } \\
\text { Warm deciduous broad-leaved shrubland (Zonality, plaigiographic climax) }\end{array}$ \\
\hline & & $\begin{array}{l}\text { 16. 常绿阔叶灌从 } \\
\text { Evergreen broad-leaved } \\
\text { shrubland }\end{array}$ & $\begin{array}{l}\text { 39)南方丘陵山地常绿阔叶灌丛(地带性，歧顶极) } \\
\text { Southern hill-montane evergreen broad-leaved shrubland (Zonality, } \\
\text { plaigiographic climax) } \\
\text { 40)滨海岛礁常绿阔叶灌从(地文顶极) } \\
\text { Seashore island evergreen broad-leaved shrubland (physiographic climax) }\end{array}$ \\
\hline & $\begin{array}{l}\text { VII. 肉质多刺灌从 } \\
\text { Thorn-succulent } \\
\text { shrubland }\end{array}$ & $\begin{array}{l}\text { 17. 肉刺灌丛 } \\
\text { Thorn-succulent shrub- } \\
\text { land }\end{array}$ & $\begin{array}{l}\text { 41)热带滨海刺灌丛(地文顶极) } \\
\text { Tropical seashore thorn-succulent shrubland (physiographic climax) } \\
\text { 42)干热河谷肉刺灌丛(地文顶极) } \\
\text { Xerothermic valley thorn-succulent shrubland (physiographic climax) }\end{array}$ \\
\hline & $\begin{array}{l}\text { VIII. 竹灌从 } \\
\text { Bamboo thicket }\end{array}$ & $\begin{array}{l}\text { 18. 竹丛 } \\
\text { Bamboo thicket }\end{array}$ & $\begin{array}{l}\text { 43)温性竹丛(地带性, 偏途顶极) } \\
\text { Warm bamboo thicket (Zonality, disclimax) } \\
\text { 44)暖热性竹丛(地带性, 偏途顶极) } \\
\text { Torrid bamboo thicket (Zonality, disclimax) }\end{array}$ \\
\hline \multirow[t]{5}{*}{$\begin{array}{c}\text { 三、草本植被 } \\
\text { Herbaceous } \\
\text { vegetation }\end{array}$} & $\begin{array}{l}\text { IX. 旱生草本植被 } \\
\text { Xeromophyic } \\
\text { herbaceous } \\
\text { vegetation }\end{array}$ & $\begin{array}{l}\text { 19. 温带草原 } \\
\text { Temperate steppe }\end{array}$ & $\begin{array}{l}\text { 45)典型草原(地带性, 气候顶极) } \\
\text { Typical steppe (Zonality, climatic climax) } \\
\text { 46)草甸草原(地带性, 气候顶极) } \\
\text { Meadow steppe (Zonality, climatic climax) } \\
\text { 47)荒漠草原(地带性, 气候顶极) } \\
\text { Desert steppe (Zonality, climatic climax) }\end{array}$ \\
\hline & & $\begin{array}{l}\text { 20. 高山草原 } \\
\text { Alpine steppe }\end{array}$ & $\begin{array}{l}\text { 48)高山寒冷草原(高山垂直带) } \\
\text { Alpine cold steppe (Alpine vertical zone) }\end{array}$ \\
\hline & & $\begin{array}{l}\text { 21. 稀树草原 } \\
\text { Tropical savanna }\end{array}$ & $\begin{array}{l}\text { 49)热带海滨稀树草原(地文顶极) } \\
\text { Tropical seashore savanna (physiographic climax) } \\
\text { 50)干热河谷稀树草原(地文顶极) } \\
\text { Xerothermic valley savanna (physiographic climax) }\end{array}$ \\
\hline & $\begin{array}{l}\text { X. 中生草本植被 } \\
\text { Mesophytic } \\
\text { herbaceous } \\
\text { vegetation }\end{array}$ & $\begin{array}{l}\text { 22. 草甸 } \\
\text { Meadow }\end{array}$ & $\begin{array}{l}\text { 51)大陆草甸(地文顶极) } \\
\text { Continent meadow (physiographic climax) } \\
\text { 52)泛滥低地草甸(地文顶极) } \\
\text { Flood plain meadow (physiographic climax) } \\
\text { 53)亚高山高山草甸(地文顶极) } \\
\text { Alpine-subalpine meadow (physiographic climax) }\end{array}$ \\
\hline & & $\begin{array}{l}\text { 23. 疏灌草坡 } \\
\text { Sparse shrub grassland }\end{array}$ & $\begin{array}{l}\text { 54)温性疏灌草坡(地带性，歧顶极) } \\
\text { Temperate sparse shrub grassland (Zonality, plaigioclimax) } \\
\text { 55)热性疏灌草坡(地带性，歧顶极) } \\
\text { Torrid sparse shrub grassland (Zonality, plaigioclimax) }\end{array}$ \\
\hline \multirow[t]{2}{*}{$\begin{array}{l}\text { 四、极端干旱植被 } \\
\text { Extreme } \\
\text { drought } \\
\text { vegetation }\end{array}$} & $\begin{array}{l}\text { XI. 荒漠 } \\
\text { Desert }\end{array}$ & $\begin{array}{l}\text { 24. 温带荒漠 } \\
\text { Temperate desert }\end{array}$ & $\begin{array}{l}\text { 56)灌木小乔木荒漠(地带性, 气候顶极) } \\
\text { Nano-arboreous fruticous dersert (Zonality, climatic climax) } \\
\text { 57)小半灌木荒漠(地带性, 气候顶极) } \\
\text { Nano-semifruticous desert (Zonality, climatic climax) } \\
\text { 58)一年生草本荒漠(地带性, 气候顶极) } \\
\text { Annual herb desert (Zonality, climatic climax) }\end{array}$ \\
\hline & & $\begin{array}{l}\text { 25. 高山荒漠 } \\
\text { Alpine desert }\end{array}$ & $\begin{array}{l}\text { 59)小半灌木高山荒漠(高山垂直带) } \\
\text { Nano-semifruticous alpine deserta (Alpine vertical zone) }\end{array}$ \\
\hline
\end{tabular}


附录I (续) Appendix I (continued)

\begin{tabular}{|c|c|c|c|}
\hline 1级 Class 1 & 2级 Class 2 & 3级 Class 3 & 4级 Class 4 \\
\hline $\begin{array}{l}\text { 植被纲 } \\
\text { Class of vegetation } \\
\text { types }\end{array}$ & $\begin{array}{l}\text { 植被亚纲 } \\
\text { Subclass of } \\
\text { vegetation types }\end{array}$ & $\begin{array}{l}\text { 植被型组 } \\
\text { Group of vegetation types }\end{array}$ & $\begin{array}{l}\text { 植被型 } \\
\text { Vegetation type }\end{array}$ \\
\hline \multirow[t]{2}{*}{$\begin{array}{l}\text { 五、极端寒冷植被 } \\
\text { Extreme frigid } \\
\text { vegetation }\end{array}$} & $\begin{array}{l}\text { XII. 高山高寒植被 } \\
\text { Alpine cold } \\
\text { vegetation }\end{array}$ & $\begin{array}{l}\text { 26. 高山冻原 } \\
\text { Alpine tundra }\end{array}$ & $\begin{array}{l}\text { 60)藓类-小灌木高山冻原(山地垂直带) } \\
\text { Dwarf-shrub moss alpine tundra (Alpine vertical zone) } \\
\text { 61)藓类-草类高山冻原(高山垂直带) } \\
\text { Herb-moss alpine tundra (Alpine vertical zone) } \\
\text { 62)地衣、藓类高山冻原(高山垂直带) } \\
\text { Lichen-moss alpine tundra (Alpine vertical zone) }\end{array}$ \\
\hline & & $\begin{array}{l}\text { 27. 高山垫状植被 } \\
\text { Alpine cushion } \\
\text { vegetation } \\
\text { 28. 高山流石堆植被 } \\
\text { Alpine scree vegetation }\end{array}$ & $\begin{array}{l}\text { 64)高山流石堆植被(地文顶极) } \\
\text { Alpine scree vegetation (physiographic climax) }\end{array}$ \\
\hline \multirow[t]{3}{*}{$\begin{array}{l}\text { 六、极端多水植被 } \\
\text { Extreme } \\
\text { waterlogging } \\
\text { vegetation }\end{array}$} & $\begin{array}{l}\text { XIII. 沼泽 } \\
\text { Swamp }\end{array}$ & $\begin{array}{l}\text { 29. 沼泽 } \\
\text { Swamps }\end{array}$ & $\begin{array}{l}\text { 65)藓类沼泽 Moss bog } \\
\text { 66)草本沼泽 Herbaceous swamp } \\
\text { 67)木本沼泽 Woody swamp }\end{array}$ \\
\hline & $\begin{array}{l}\text { XIV. 水生植被 } \\
\text { Aquatic } \\
\text { vegetation }\end{array}$ & $\begin{array}{l}\text { 30. 淡水水生植被 } \\
\text { Fresh water vegetation }\end{array}$ & $\begin{array}{l}\text { 68)沉水植物群落 Submerged plant community } \\
69) \text { 漂浮植物群落 Free floating plant community } \\
\text { 70)浮叶植物群落 Rooted floating-leaved plant community } \\
\text { 71)挺水植物群落 Emergent plant community }\end{array}$ \\
\hline & & $\begin{array}{l}\text { 31. 咸水水生植被 } \\
\text { Salt water vegetation }\end{array}$ & 72)咸水沉水植物群落 Salt water submerged plant community \\
\hline
\end{tabular}

引自: 宋永昌(2011)。3级植被型组和4级植被型作了较大调整。

Cited from Song YC (2011). The class 3 (Group of vegetation types) and the class 4 (Vegetation type) were largely updated. 